\title{
La música en las aldeas de la Amazonia portuguesa (siglo XVII)
}

\author{
Luisa Tombini Wittmann \\ (UNICAMP)
}

A comienzos del siglo XVII, la Compañía de Jesús extendió sus actividades de evangelización desde la costa de Brasil hacia el espacio amazónico, siguiendo la estela de la expansión portuguesa por el norte. Los padres Francisco Pinto y Luís Figueira fueron pioneros de un largo viaje, cuya finalidad era atravesar la región del noreste hasta Maranhão. El intento evangelizador de los misioneros que partieron en dirección a la Sierra de Ibiapaba en el año de 1607 terminó drásticamente con la muerte del padre Pinto a manos de los indios cararijús. Décadas pasaron, pero el destino trágico no abandonó al jesuita Figueira. Cuando volvía de Portugal, en el que sería su último viaje para establecer una misión en Pará, naufragó por los alrededores de Belém. Logró alcanzar en una balsa la tierra firme de la isla de Marajó, pero fue asesinado por los indios aruás en la guerra contra los portugueses.

La expulsión de los franceses de São Luís de Maranhão, en donde habían fundado la Francia Equinoccial en 1612, contó con la participación de los jesuitas Manuel Gomes y Diogo Nunes, quienes se mantuvieron en la isla por algunos años. A partir de 1615, los portugueses intensificaron su proyecto de controlar el litoral norte - llamado costa este-oeste para diferenciarlo de la costa norte-sur, entre el noreste y el sur de la colonia -, hasta la naciente del río Amazonas. En ese lugar todavía existían ingleses, irlandeses y holandeses disputándose la ocupación y la explotación de la región, interés que incluía la mano de obra indígena. Mediante una orden del rey, el 21 de marzo de 1624 fue definida la separación entre el Estado de Brasil y el Estado de Maranhão y Gran Pará, debido a la dificultad de navegación marítima entre Pernambuco y Maranhão, las disputas entre los países europeos por la región norte y su enorme dimensión. La ley oficializó la independencia administrativa de este Estado, formado por las capitanías de Ceará, Piauí, Maranhão, Pará y 
Amazonas, el cual pasó a estar directamente subordinado a Lisboa.

Las misiones religiosas fueron, al lado de las acciones militares de las tropas de guerra y rescate, las principales responsables por la ampliación de las fronteras portuguesas hacia el interior de los ríos y de las selvas amazónicas. Para eso, fue imprescindible la formación de alianzas con las diversas poblaciones indígenas y sus jefes. A los nativos aliados de otros extranjeros, en combate con los portugueses, les fue declarada la guerra. Las naciones indígenas, por tanto, tuvieron una participación activa en este proceso, formando enemistades o alianzas maleables con los europeos y entre sí, tomando en consideración los intereses de cada etnia. En este escenario, algunos ignacianos se alistaban en evangelizaciones temporales, para diseminar ideas cristianas durante las visitas que hacían por las aldeas indígenas.

El padre Antonio Vieira desembarcó en el Estado de Maranhão y Gran Pará a comienzos de 1653, ejerciendo el cargo de superior de la misión hasta 1661. Este fue el año en que los jesuitas fueron expulsados por primera vez, aunque sólo por un corto período, de Maranhão. Las razones estaban relacionadas con los conflictos frecuentes que los religiosos tenían con las autoridades y los colonos, sobre todo en relación con la mano de obra indígena, anhelada por estos y controlada por los otros. A partir de la mitad del siglo XVII, el proyecto evangelizador ignaciano en la parte norte de la colonia portuguesa fue desarrollándose con el establecimiento de residencias, iglesias y aldeas. Con la intención de organizar la misión, Antonio Vieira escribió el célebre "Reglamento de las aldeas", mejor conocido como "Visita de Vieira", en el cual establece reglas a ser seguidas inclusive por otras órdenes religiosas ya que la Compañía de Jesús tenía primacía absoluta en la actividad catequizadora de los indígenas.

Las directrices apuntadas por este documento rigieron por más de un siglo, hasta la expulsión definitiva de los jesuitas de la América portuguesa en 1759. El reglamento abarca desde cuestiones catequéticas y de organización de las aldeas hasta especiales orientaciones y cuidados necesarios para los misioneros durante su estadía en lugares inhóspitos y tentadores. La preservación moral de los misioneros era una preocupación constante para Vieira, que define una rígida separación entre la casa de los padres y la de los indios, además de prohibir la presencia de mujeres en las canoas donde viajaban los religiosos. Al salir los primeros rayos de sol en la aldea, la misa ya debía estar llevándose a cabo. Una vez finalizada, eran enseñadas y recitadas en voz 
alta las oraciones ordinarias. Después de estas obligaciones sacramentales y doctrinales, los indios se dirigían a sus labores y los niños a las escuelas. En ese ambiente se debería enseñar, en palabras de Vieira, "a leer y escribir, y habiendo muchos se enseñará también a cantar y tocar instrumentos para beneficiar los oficios divinos; $\mathrm{y}$ cuando menos, se enseñará a todos la doctrina cristiana" (LEITE 1943: 112).

Como Manuel de Nóbrega, Antonio Vieira creía en la música como un medio eficaz para la comunicación y la evangelización de los indios. De esta manera, trabajó por la continuación de su uso como parte constitutiva de las actividades desarrolladas por los miembros de la Compañía de Jesús en Brasil, incluso siendo que en otros contextos misioneros, como en la India, se manifestaron dudas a causa de las restricciones musicales presentes en las Constituciones ignacianas. En el año de 1653, cuando llegó a Maranhão, Vieira relató de forma elogiosa en carta al provincial las alabanzas cantadas para Nuestra Señora, y alertó que "no ha de parecer cosa extraña de nuestro instituto, antes muy propia, pues es traer las almas hacia Dios por las todas las maneras" (VIEIRA 1997: 338).

La experiencia de la misión del norte, en la cual Vieira tuvo una importante participación, inspiró las directrices que el padre escribió. La rutina de las aldeas jesuitas, que determinó también las cartas de Nóbrega en el siglo anterior, direccionó las prácticas de conversión. Heredero de su compañero de orden, Vieira tenía conocimiento de las experiencias de los primeros jesuitas, que vivieron entre los tupis en la costa del Estado de Brasil. Un siglo después de la polémica entre Nóbrega y el obispo Sardinha, ya no era necesario justificar de manera tan vehemente el uso de la música en las misiones jesuitas que estaban siendo establecidas, a partir de la mitad del siglo XVII, en la parte norte de la colonia portuguesa. Sin embargo, Vieira insistió en evocar a Nóbrega en su argumentación sobre el papel de la música en la edificación espiritual de los indios de la Amazonia portuguesa.

Desde el primer día comenzaron los padres a enseñar la doctrina en el campo, a la que acudieron principalmente los pequeños que muy brevemente aprendieron de memoria las oraciones, y respondieron con prontitud a todas las preguntas del catecismo. Pero después que los padres les enseñaron a cantar los propios misterios, que compusieron en versos y con tonos muy agradables, se vio con cuánta razón decía el padre Nóbrega, primer misionero de Brasil, que 
con música y armonía de voces lograría atraer a todos los paganos de América. Fueron de aquí en adelante muchos mayores los concursos y adoctrinamientos de todos los indios, y mayores también las esperanzas que los padres generaron de que por medio de esta música del cielo quería el divino Orfeo rescatar las almas de las fieras de estas peñas, para atraerlas al edificio de su iglesia (VIEIRA 1904: 117).

La cultura oral indígena facilitó la memorización del catecismo. Fue, sin embargo, su versión cantada la que tuvo mayor impacto entre los indios. Los versos musicalizados por los propios jesuitas reforzaron sus esperanzas en relación al éxito de la misión, y también trajeron la memoria de Nóbrega, quien difundió entre los jesuitas la intención de catequizar a todos los pueblos de América a través de la música. Era ésta, más que los sermones, la que encantaba los oídos de los indios y la que podría transformarlos de seres animalizados en representantes ejemplares de la Iglesia Católica.

Es bien sabido a través de las narraciones jesuitas que los indios americanos acostumbraban a realizar rituales religiosos utilizando la música como medio de conexión con la divinidad. Al conocer a los padres jesuitas, quienes se presentaban como líderes espirituales, demostraron gran interés en oír y aprender su sonoridad. Los misioneros que partían para establecer la misión del norte ya tenían conocimiento - a través de la propia experiencia o de las informaciones obtenidas de otros compañeros de la orden - de la importancia de la música en la cultura indígena. Por eso llevaron consigo, en el penoso viaje desde Pernambuco hasta Maranhão, algunos músicos tupis. Los indios cristianos fueron para auxiliar a los jesuitas en las tareas de catequización, sobre todo para enseñar las músicas religiosas que habían aprendido en las aldeas del Estado de Brasil. El misionero Luís Figueira relata, respecto de los indios de la etnia Potiguar:

Son todos estos increíblemente dados a cantar y a danzar y porque los pitiguare son en esto afamados y con nosotros habían algunos nheengaraybos, o maestros de capilla destinados a que cantasen para enseñarles, y haciendo relevo cada hora cantaban día y noches de 24 en 24 horas sin interrupción hasta que no podían hablar de tan roncos teniendo esto por valentía y delirio, y nos pedían que les enseñásemos a sus hijos el papel (como ellos lo llamaban) queriendo decir que les enseñásemos a leer y a cantar nuestro canto, lo que nosotros con facilidad hacíamos para domesticarlos (...) También lo hacíamos enseñándoles 
a danzar a la manera de los portugueses que para ellos era de sumo placer. (FIGUEIRA 1940: 129-130).

Aunque los padres jesuitas exaltasen la permeabilidad de la cultura indígena, conquistada a través de la música, dejan entrever también, en sus relatos, los límites de sus acciones catequizadoras. La utilización de los cánticos religiosos en un formato mucho más parecido al de los rituales chamánicos que al de las celebraciones católicas es un indicio que no puede ser ignorado. En las manifestaciones indígenas de religiosidad el canto incesante que provoca el trance abría un canal de contacto con lo sobrenatural. En este caso, en vez de un verdadero deseo indígena por la conversión a la fe cristiana, como desearía el misionero, los potiguares debieron haber utilizado la musicalidad ignaciana con otros propósitos. Intentaron, tal vez, a través de un contacto incipiente y sin un diálogo intenso con la creencia católica, apropiarse de los poderes espirituales de los jesuitas a través del aprendizaje de su sonoridad, por tratarse de una vía espiritual que para ellos tenía sentido. Este proceso implicó una resignificación de símbolos y prácticas religiosas y musicales. El autor del relato citado prefiere relatar una domesticación inminente siendo que, incluso, aquella gestualidad musical causó otros efectos. Había un sentido cristiano que todavía no había sido absorbido ni era manifestado de acuerdo con los parámetros europeos por parte de una etnia recién contactada.

El nombre dado por el padre Figueira a los tupis músicos merece especial atención: Nheengaraibas. Dice Serafim Leite que "eran maestros cantores o, como traduce, medio etimológica medio humorísticamente, Luís Figueira, 'maestros de capilla"' (LEITE 1947: 379). Eran músicos que no servían directamente a la Iglesia, a un Rey o a un Papa, teniendo como oficio tocar y cantar en castillos y templos europeos. Su función, en América, era catequizar a la gente a través de la música, en una vida itinerante. Su distinción era hablar y escribir en la lengua del blanco, era cantar a la manera europea. Por eso, tal vez, el nombre inventado por Figueira, en la unión de las palabras tupi nhe'enga (lengua, idioma) y karaiba (hombre blanco). El idioma aquí no era solamente hablado, era cantado, lo que interesaba mucho más a los indios $\mathrm{y}$, por tanto, se tornaba sumamente efectivo en el establecimiento de un contacto que a veces aún no era lingüístico.

El interés que tenían los indígenas en aprender la sonoridad del otro, con intentos que superaban el gusto o la mera curiosidad, hizo que rápidamente participasen como músicos de celebraciones católicas, sobre todo, misas y 
procesiones, muy frecuentes en las aldeas coloniales. En los cortejos generalmente cantaban las letanías católicas y cargaban la cruz o, dependiendo de la ocasión, la imagen de un santo, de Cristo o de la Virgen María. En una procesión realizada en 1653, un principal llevó la imagen de San Ignacio de Loyola, mientras indios e indias separados en filas entonaban cantos cristianos. Al llegar a la iglesia matriz continuaron apartados, de un lado los hombres y de otro las mujeres, y oyeron al padre conceder premios a los que mejor respondían a las preguntas del catecismo. Esta actividad formaba parte de una dimensión pedagógica jesuita más amplia, que incluía la enseñanza de la lectura, la escritura y el canto. En el año siguiente de su llegada - dice Vieira -, prosiguieron los servicios de Dios y hubo inclusive sacramentos realizados durante la noche; así de grande era la demanda existente. Durante la cuaresma, registra con satisfacción el alto número de ciento veintitrés sesiones de confesión.

Al entrar en la sierra de Ibiapaba en 1656, en pleno miércoles de Semana Santa, Vieira y otros misioneros tuvieron que organizar rápidamente los cultos religiosos. Al final, era la época más importante del calendario de la Cristiandad. Para eso, contaron con la ayuda de los indios músicos, que vinieron desde Pernambuco para realizar los oficios divinos con canto de órgano (BETTENDORF 1909: 96). En la puesta del sol del viernes de la pasión se reunieron todos para la llamada "procesión del entierro de Cristo". Según Vieira, todo ocurrió con mucha devoción y solemnidad. En São Luís de Maranhão, la iglesia matriz fue dedicada a Nuestra Señora, pues la victoria contra los franceses le fue atribuida a ella. El éxito de los portugueses en 1615 era considerado uno de sus milagros. Siendo así, todos los años su día era celebrado con una solemne procesión, misa cantada y tiros de artillería. En las celebraciones dedicadas a la Virgen María estaba incluido el rosario, una oración católica contrarreformista que acabó difundiéndose por las misiones del norte'. De acuerdo con João Felipe Bettendorf, fue Antonio Vieira quien estipuló y estimuló la oración del rosario, rezado a coro, durante los viajes que cruzaban el Atlántico y las celebraciones en las iglesias del Estado de Maranhão y Gran

1 Para mayores informaciones sobre la práctica de recitación del rosario en Portugal y en la América portuguesa, su estructura de oraciones y sus características musicológicas - reconstrucción hecha a través de las relaciones establecidas con una partitura del siglo XVIII, del compositor Emerico Lobo de Mesquita -, ver CASTAGNA, Paulo. 1999. "Uma abordagem musicológica da produção literária de Antônio Vieira (1608-1697)”. Cadernos do IEB/USP. Antônio Vieira: o imperador do púlpito: 39-72. 
Pará2. Para que la costumbre no se perdiese a lo largo del tiempo, Vieira dispuso que una cofradía se responsabilizase por la actividad, habiendo siempre durante las oraciones dos hermanos religiosos sosteniendo antorchas encendidas y otros cantando las letanías y el Ave María. El éxito de Vieira se evidencia gracias a la información de que los rosarios cantados a coro continuaron siendo practicados, incluso, después de la expulsión en el año 1661.

Antonio Vieira fue un gran incentivador de las ceremonias católicas con música. Su inclusión como una importante aliada en el proceso de evangelización fue común entre los jesuitas en las misiones de la América portuguesa. Podemos decir, incluso, de manera general, que Vieira se fundamentó en el trabajo de Nóbrega. Hubo, sin embargo, diferencias y semejanzas en las prácticas misioneras de la costa y del norte, separadas temporal y geográficamente por, por lo menos, un siglo y una gran sierra. A pesar del argumento justificativo de querer seguir con la misma intención -atraer indios americanos para la fe católica - nuevas prácticas y sujetos surgieron en el contexto del norte. Uno no fue copia del otro. A pesar de portar herencias del siglo pasado, las singularidades determinaron las historias de los jesuitas y los indios de la Amazonia.

En las aldeas del Estado de Maranhão y Gran Pará resonaron el rosario y los cantos de los indios tupi cristianizados. En el siglo XVI, el Rosario de la Virgen no era conocido, haciéndose mención a otro, al Rosario del Nombre de Jesús. En aquellos tiempos iniciales de la misión ignaciana, quienes participaron efectivamente de la catequización a través de la música no fueron los Nheengaraibas, y sí los huérfanos venidos de Lisboa, quienes aprendieron a cantar y tocar músicas indígenas y hasta les cortaron el cabello al estilo de los curumins, con la intención de asemejarlos a los nativos. No podemos, por lo tanto, exagerar el peso que tuvieron los modelos de la metrópoli sobre las prácticas de la colonia, cualquiera que estos hayan sido.

$\mathrm{Al}$ valorizar de forma excesiva una supuesta importación de costumbres religiosas portuguesas perdemos de vista la riqueza y la complejidad de su intento de infiltración en el territorio indígena. Todavía más grave, pueden

2 Al llegar a São Luís, después de hacer algunas visitas a las aldeas indígenas, "trató el sub prior de toda la misión de poner al corriente todas las funciones de la Compañía de Jesús. Instituyó el rosario que cada día por las cinco horas de la tarde después de la clase era cantado por los estudiantes y muchachos de la escuela delante de la imagen de Nuestra Señora de la Luz, que estaba en el altar mayor" (BETTENDORF 1909: 78). 
escapársenos algunas diferencias fundamentales entre las experiencias misioneras, como la alteración de la práctica del quinientos - que tanto atemorizó al obispo Sardinha - de tocar instrumentos indígenas. Sobre todo, sacudir las maracas sagradas que, en la parte norte de la colonia portuguesa, van a aparecer solamente en las manos indígenas. Este es un indicio significativo de que los jesuitas, después de décadas de misión, percibieron el riesgo que corrían al manosear instrumentos sagrados tan arraigados en la religiosidad indígena y, por tanto, en los poderes de los chamanes. Probablemente, ésta fue una decisión tomada por los padres a través de los debates teológicos. Los jesuitas, sin embargo, prefirieron no registrar el tópico en sus correspondencias, tal vez para ahorrarles una crítica a los colegas que iniciaron la misión liderada por Nóbrega.

El hecho es que, en lo referente a la música, prefirieron manifestarse por medio de formas más cercanas a las costumbres europeas. Lo que, no obstante, no confirma que la musicalidad en las aldeas del norte fuese única. Es necesario recordar, en conformidad con las fuentes como aquella sobre los potiguares, que la expresión sonora en las aldeas podía distanciarse completamente de las ordenadas solemnidades citadas. La cultura indígena se manifestó hasta cuando cantaban en grupos las oraciones cristianas, pues lo hacían bailando día y noche sin interrupciones. Para los indios, la experiencia del cuerpo era evidente. La del tiempo, extendida. La espiritualidad indígena no era racionalizada como la de los letrados jesuitas, pero sí era sensorial, corporal, musical.

Los indios determinaron la vida musical de las aldeas como participantes activos que eran de las celebraciones religiosas. Algunas veces reproducían lo que les era enseñado de manera ejemplar, lo que no denota una simple pérdida de sus propios valores culturales, como quisieran algunos autores. Otras veces, continuaron realizando sus rituales tradicionales, aunque con modificaciones. En otras, además, percibimos la fusión de símbolos católicos e indígenas. Son los efectos de un contacto establecido entre por lo menos dos sujetos, si utilizamos la terminología genérica de blancos e indios, los cuales no permanecieron intactos en el transcurrir de las relaciones sociales. Siendo así, la música católica no fue el único estilo que se oyó en las aldeas jesuitas de aquellos Estados coloniales. Desde la llegada de los jesuitas a la costa de Brasil en 1549, se pueden identificar diversas prácticas musicales en el Nuevo Mundo. A pesar de que los jesuitas optaron muchas veces por divulgar 
las descripciones de las ceremonias en las aldeas como semejantes a las de Europa, éstas no deben ser valoradas en exceso. Al final de cuentas, además de la divulgación de tal éxito - que respondía a un interés ignaciano - también forman parte de las narraciones jesuitas algunas performances que los padres hubieran preferido no testimoniar pero que tuvieron que negociar.

Valiéndose de la experiencia de más de un siglo de misión jesuita en Brasil, Antonio Vieira hace la siguiente revelación, un año después de su llegada a Maranhão: "Ni nosotros le quitamos o le prohibimos su canto y baile, ni tampoco beber y alegrase, siempre que sea con la moderación debida; no hacemos la ley de Cristo pesada y triste, cuando ella es jugo suave y leve" (VIEIRA 1997: 378). El rígido estilo de vida cristiano se adapta para conquistar un nuevo público: el indígena. Los jesuitas sabían de los riesgos de las exigencias y de las prohibiciones inmediatas y exacerbadas, y se dieron cuenta de la necesidad de hacer concesiones a los indios. Al final de la primera década de intensificación de la misión de la Compañía de Jesús en la región, Vieira decretó:

Para que los indios se sientan en la capacidad de participar en los oficios divinos y de entender la doctrina, como conviene, se les consentirán sus bailes en la víspera de los domingos y días santos, hasta las diez horas u once de la noche solamente, y para que acaben aquellos bailes, se tocará la campana y se recogerán en sus casas (LEITE 1943: 113).

Es recurrente el intento de controlar el tiempo. La campana marca la búsqueda de una temporalidad basada en la rutina de las actividades cristianas, pero también revela la flexibilidad de estas prácticas. Si las fiestas indígenas sufrían apenas una restricción de horario, en los días que precedían a celebraciones católicas específicas, podemos inferir, en primer lugar, que eran frecuentes, incluso, dentro del espacio de las propias aldeas jesuitas. En segundo, que se extendían muchas veces hasta la madrugada, escapando al orden cuadriculado de los días, tan común a la lógica occidental. El fin de la fiesta indígena, cuando era estipulado, estaba definido por el sonido de la campana, utilizada además para iniciar y finalizar diariamente las actividades religiosas y laborales de los indios aldeanos, que incluían cantar en las misas y trabajar en el monte.

Los misioneros jesuitas llegaron a incentivar costumbres condenatorias, ligadas a los rituales paganos, en la medida en que conseguían la 
participación de los indios en los ritos católicos, o incluso una alianza estratégica entre pueblos nativos rivales. En las aldeas de los tapajós, en un claro proceso de negociación, la principaleza Moacara pide y recibe del superior un frasco de aguardiente a cambio de las paces con otras etnias 3 . En otras ocasiones, la bebida fue un elemento provocador, accionado por los indios. Además, de acuerdo con el padre João Felipe Bettendorf, la rebeldía de los caycayzes se hizo visible - y audible - en las performances que se realizaban por los montes de Maranhão y por las calles de São Luís: “Aturdiendo con sus cantos desentonados a los religiosos del Collegio y a todos los vecinos, y mucho más cuando habían bebido una gota de aguardiente, del cual son tan amigos todos los indios" (BETTENDORF 1909: 513). Las acciones indígenas revelan cuán paradójico podía ser el ofrecimiento de bebidas alcohólicas por los propios misioneros. Al mismo tiempo en que servían de ayuda para la formación de las alianzas y las conversiones, también podía amenazarlas.

El padre João Felipe Bettendorf también registró la continuación de las fiestas tradicionales indígenas en un espacio destinado para la ejecución de los rituales de los tapajós. ${ }^{4}$ En un área situada en el interior de la selva, pero no muy distante de la aldea, los indios estaban comunicándose con el diablo, escribió Bettendorf. Por este motivo, resolvió prohibir las idas para el monte. Para tener alguna posibilidad de éxito, abrió una excepción: "Yendo yo mismo a ver aquel terreno, para después prohibirlo, como lo hice, dándole sólo permiso para beber en su casas" (BETTENDORF 1909: 170). Pero incluso permitiendo bebidas alcohólicas dentro de la aldea, a Bettendorf no le fue respetada la restricción impuesta en el espacio de la fiesta. Al ver hombres y mujeres con niños en brazos o de la mano, e igaçabas de vino en la cabeza, Bettendorf descubrió que los indios aldeanos estaban yendo a beber y a realizar sus bailes llamados poracés en el "terreiro del diablo". Contó con la ayuda

3 Otros ejemplos de los usos del aguardiente como bebida de negociación y vehículo para el control del cuerpo y de las almas de los poblados del Amazonas colonial pueden ser encontrados en CARVALHO JÚNIOR, Almir Diniz de. 2005. Índios cristãos: a conversão dos gentios da Amazônia Portuguesa (1653-1769). Tese de Doutorado em História, Universidade Estadual de Campinas, pp. 175-183.

4 La misión fundada por Bettendorf, en la naciente del río del mismo nombre, dio origen a la ciudad de Santarém en Pará. El jesuita llegó a São Luís en 1661, atendiendo al pedido del entonces superior de la orden en Maranhão, Antonio Vieira. Permaneció en el norte durante casi cuatro décadas, ejerciendo funciones diversas como misionero de las aldeas, rector de los colegios jesuitas de São Luís y de Belém y superior de toda la misión de la Compañía en el Estado de Maranhão y Gran Pará. Para la redacción de su famosa crónica, finalizada en el año de su muerte, 1698, Bettendorf se basó en informaciones recogidas entre los colegas misioneros, en cartas ignacianas y en la propia experiencia personal. 
de João Correa, que obedeciendo la decisión de Bettendorf, ordenó que todos volviesen inmediatamente para sus casas. Y como los indios insistían en desobedecer, Correa asumió una actitud extrema al quebrar con un pedazo de palo algunos recipientes, derramando el vino que contenían. Bettendorf nos presenta un desenlace favorable para los jesuitas, pero revelándonos, al mismo tiempo, más sobre la experiencia misionera de exigencias y concesiones.

Se fueron todos para sus casas y nunca más fueron al terreno prohibido, mientras los vigilaba; sin embargo, para no ir del todo en contra de aquellos principios, les permití que visitasen las casas de unos y de otros, y que allí bebiesen con moderación. Había también otro terreno dentro de la misma aldea, al que los blancos llamaban Mofana; éste tampoco se frecuentó más y así quedaron abandonados los terrenos de donde los diablos sacaban enorme provecho del desorden que allí se suscitaba con las continuas bebederas y bailes (BETTENDORF 1909: 171).

Los rituales indígenas eran considerados como maléficos por parte de los misioneros, que muchas veces los clasificaban como resultado de la acción del demonio sobre las ovejas que añoraban catequizar. Así mismo, Bettendorf nos revela una vez más que hubo consentimiento, por parte de los jesuitas, en relación a los festejos indígenas. El relato trata sobre las visitas que hizo a Pará en el año de 1663, en compañía del gobernador Ruy Vaz de Siqueira. Después de haber sido recibidos por los indios, convocaron a estos últimos para el adoctrinamiento. Una vez terminadas las lecciones catequéticas, registró Bettendorf: "Los dejábamos hacer sus danzas por la tardecita" (BETTENDORF 1909: 220). Estas no eran aldeas jesuitas sino indígenas, donde se infiere que eran mantenidas sus costumbres con mucha más facilidad y frecuencia, ya que los misioneros aparecían sólo en visitas esporádicas. Cierta vez, Antonio Vieira recibió informaciones de terceros sobre el escenario de la muerte del padre Figueira, donde días después aún se podía ver mucha sangre. Vieira escribió con desconfianza sobre aquellas gentes paganas, con las cuales los misioneros no tuvieron tiempo de establecer un contacto más frecuente.

A este palo los ataban uno por uno en diferentes días, y luego se juntaban alrededor de ellos con gran fiesta y algarabía, todos con sus palos de matar en las manos. (...) Armados de esta manera andan saltando y cantando, rodeando a los que han de morir, y llegada la hora en que ya no pueden contener más su 
fiereza, descargan con fuerza sus palos de matar y con ellos les quiebran las cabezas (VIEIRA 1997: 379)

Es cierto que había conflictos constantes en relación a las manifestaciones indígenas, fuesen antropofágicas o no. Sin embargo, la persistencia de los catecúmenos en mantener algunas de sus antiguas costumbres forzó a los jesuitas a flexibilizar sus reglas de comportamiento, al punto de ser registradas concesiones hechas a los indios en narraciones oficiales como la crónica de Bettendorf y el reglamento de Vieira. Existían las leyes de las aldeas, impuestas a los moradores por los jesuitas, pero son las prácticas desarrolladas en el día a día las que nos dan la dinámica de la historia. En la cotidianidad de las misiones, la negociación era de hecho la regla entre jesuitas e indios.

Al fracasar en la exterminación definitiva de los rituales indígenas, los padres buscaron controlar su tiempo y espacio con límites de horario y mudanzas de lugar para sus realizaciones, a pesar del efecto negativo que consideraban que traían aquellas ceremonias para la evangelización. Los ignacianos sabían que una prohibición radical podría traer todavía más problemas. En este sentido, el pensamiento de Bettendorf es sabio y aclaratorio: "No ir del todo en contra de aquellos principios". Era el inicio de la misión en la parte norte de la colonia portuguesa, pero se trataba de un principio respaldado por una larga presencia ignaciana entre los indios de América. Contacto repleto de traducciones culturales ${ }^{5}$, que muchas veces transcurrían por la vía musical.

La crónica de João Felipe Bettendorf relata también el episodio de cuando los guajajaras fueron llevados a una aldea ignaciana. El jesuita cuenta que estos indios vinieron al ritmo de una gaitinh $a^{6}$, tocada por el padre João Maria Gorsony, que quiso alegrarlos por el camino. El misionero fue a buscarlos personalmente así que se dio cuenta de la ausencia de algunos, que

5 Ver POMPA, Cristina. 2003. Religião como tradução: missionários, Tupi e Tapuia no Brasil colonial. Bauru: EDUSC.

6 De acuerdo con el diccionario de Raphael Bluteau, gaita es sinónimo de flauta. Los términos musicales referentes a los instrumentos citados en los documentos jesuitas son generalmente imprecisos. El musicólogo Marcos Holler afirma que, por la facilidad de construcción y ejecución, las flautas mencionadas en el período colonial deben ser instrumentos rústicos de bisel, y no una gaita gallega, comunes en los países ibéricos (HOLLER 2010: 105). Las flautas indígenas, hechas de huesos humanos, eran llamadas cangüera por los tupinambas. Para mayores informaciones acerca de los instrumentos musicales del período, ver HOLLER, Marcos. 2010. Os jesuítas e a música no Brasil colonial. Campinas, SP: Editora da Unicamp e CASTAGNA, Paulo. 1991. Fontes bibliográficas para a pesquisa da prática musical nos séculos XVI $e$ XVII. Dissertação de Mestrado em Artes, Universidade de São Paulo - São Paulo. 
probablemente huyeron por el monte, quienes antes habían sido traídos por el padre Manoel Nunes. Al llegar cerca de la residencia de Nuestra Señora de la Inmaculada Concepción en Cayritiba, en la aldea del río Pinaré, cuenta Bettendorf:

Fui a recibirlos con trompetas a la puerta y los llevé con algarabía a la iglesia (...) El padre João Maria los enseñó a tocar la gaitinha, y así los convirtió en aficionados a este instrumento, y están tocando por las noches y los días, cuando están desocupados; no hay dudas que uno de los mejores medios para entretenerlos e inspirarlos para estar cerca de los padres es enseñarlos a tocar algún instrumento para sus celebraciones en sus días de fiesta en las que hacen sus procesiones y danzas, teniendo delante de sí a la imagen de Nuestra Virgen Señora, alternando con cantos: Tupa cy angaturana, Santa María Christo Yara (BETTENDORF 1909; 271-2).

El jesuita Bettendorf entiende la música en este fragmento como una manera de entretener y retener a los indios, conjugando el éxito de la llegada de los guajajaras y de las fiestas católicas en la que participaron con la gaitinha tocada por el padre Gorsony. Al no evidenciar la gestualidad musical indígena como parte significativa de su religiosidad, Bettendorf, así como los otros misioneros, parecían creer que el interés que los indios tenían en la música era apenas como un entretenimiento, o preferían registrarla de ese modo. Sin embargo, el deseo de aprender las canciones de los misioneros y de dominar sus instrumentos, reflejaba la creencia indígena en el poder espiritual de la experiencia musical. Los relatos en los que se muestra el interés, algunas veces el miedo, que los indios tenían en los poderes de los padres, hace evidente que no se trataba sólo de un aprendizaje ingenuo de la música religiosa europea. Al final, la elección de los misioneros por el universo del sonido como canal de conexión con el mundo sobrenatural seguía la lógica de los nativos que, al contrario de los jesuitas, reservaban para la música y para sus instrumentos un lugar central en la religiosidad.

La llegada al poblado fue festejada al son de las trompetas, lo que refuerza el interés de los indios, bien conocido por los jesuitas, por los instrumentos de viento. Otros escritos ignacianos traen descripciones de flautas indígenas hechas de huesos de animales o incluso de humanos. Es común también el registro de la forma incansable que tenían los indígenas de tocar y de cantar. Conjuntamente, en el caso de los guajajaras quedó registrada la presencia 
de danzas indígenas y de la imagen de la Virgen. Estamos delante de una demostración católico-tupi, únicamente posible en un contexto de contacto, y de una participación indígena que es esencialmente musical. Es interesante notar el sentido cristiano de la música, cantada en lengua general, cuya interpretación indígena es de difícil investigación. Dios es llamado Tupã, pero los nombres de María y Cristo no fueron traducidos. Sin encontrar una referencia precisa en la cultura y en la lengua indígena, los jesuitas optaron por sustituir solamente a la divinidad central por la palabra que designaba el fenómeno natural del trueno, por el cual los indios demostraban respeto y temor.

La documentación jesuita es rica en descripciones de ceremonias católicas y dejó indicios de que muchas veces ellas se convertían en manifestaciones religiosas mixtas, con la presencia conjugada de símbolos indígenas y católicos. Al llegar a la Sierra de Ibiapaba durante la Semana Santa, por ejemplo, los jesuitas tuvieron ayuda de los indios músicos tupi en la celebración de una misa con canto de órgano. Hubo también una procesión, yendo al frente muchachos indígenas con coronas de espinas y cruces a cuestas. Al regreso, registró Vieira, estaban "todos los indios arrastrando los arcos y las flechas al son de los cajones destemperados"7 (VIEIRA 1904: 136). Es interesante notar la introducción de instrumentos de guerra indígenas en una austera procesión del calvario de Cristo. Es difícil llegar a una conclusión sobre lo que pensaban los indios que participaban de este cortejo, pero podemos inferir qué amalgamas se generaban constantemente en la comunicación entre sujetos, cosmologías y universos tan distintos. De hecho, el momento por excelencia de la traducción cultural fueron los espectáculos religiosos transcurridos en las aldeas, con códigos indígenas y diversas sonoridades. De acuerdo con Castelnau-L'Estoile, los jesuitas se valieron de las fiestas, en detrimento de la imagen, como estrategia de conversión de los indios en Brasil.

Las fiestas surgen como un lenguaje en común entre ellos y los indios, una pasarela entre los dos mundos. Para seducir a los indios de México, herederos de una larga tradición iconográfica y pictórica, los misioneros recurrieron a las

7 El término cajón tiene varios significados en la música, que se refieren a recipientes cerrados para guardar instrumentos y que hacen vibrar a los instrumentos de cuerda. En este caso relatado por Vieira debe equivaler a tambor, pues es utilizado en una representación de un servicio fúnebre. Conforme Bluteau, la caja era en la época sinónimo de tambor, y destemperar las cajas sería como tocar confusamente y sin orden. Tambor, dicho de forma general, es un membranófono percutido de doble cara, teniendo formas y tamaños variados. 
imágenes occidentales. En Brasil, en donde el intento del catolicismo ilustrado fue un fracaso, la fiesta tomó el lugar de la imagen. En las descripciones de los indios hechas por los jesuitas, el indio es frecuentemente presentado como un guerrero, o en la fiesta, logrando cantar y bailar varios días seguidos sin jamás descansar. Los jesuitas usaron, por tanto, conscientemente, elementos del mundo indígena para intentar introducir las fiestas cristianas entre los indios. (CASTELNAU-L'ESTOILE 2006: 511).

La fiesta ocupaba un espacio central en la cultura indígena, como bien dice la autora, al punto de que sus gestos y músicas fueron integrados en las descripciones y en las celebraciones de los jesuitas. No obstante, además del uso consciente por parte de los misioneros de tales elementos como forma de manipulación de las creencias indígenas, debemos apuntar hacia la posible y probable autonomía de los nativos en este proceso de diálogo religioso. También de forma consciente, los indios vivenciaron e interpretaron la nueva coyuntura delante de la fusión de símbolos religiosos y del aprendizaje musical. Pudieron, incluso, haber pretendido apropiarse de los poderes de los líderes de la otra creencia religiosa, realizando una especie de antropofagia sonora al devorar estímulos y capacidades musicales de los padres jesuitas.

El caso más radical, relacionado con las disputas religiosas entre indios y blancos en las tierras del norte, ocurrió en el Cabo Norte en 1688. Los jesuitas Antonio Pereira y Bernardo Gomes, a solo dos meses de haberse instalado en el lugar, fueron asesinados por los indios de la etnia Aguaraca, en la isla de Camunixary. Independientemente de la ruptura con los jesuitas y del fracaso de esta misión, la música tuvo un lugar interesante en esta historia. Un caso singular no porque resonase durante el conflicto, sino porque aquella fue escuchada después del fallecimiento de los jesuitas. Los propios enemigos, después de muertos, fueron transformados en instrumentos musicales.

Después de la matanza desnudaron los cuerpos muertos y los guindaron desnudos en las vigas de las casas, los picaron en pedazos, los asaron y se los comieron, guardando, sin embargo, los cráneos para beber sus vinos en ellos, y algunas canillas para hacer sus flautas y las puntas de sus flechas, como también la grasa y la manteca para untarse con ellas. (...) El indio Moximaré, de la aldea de Mucurá, del pueblo Maraunizes, con otros tres compañeros robó una canilla del padre Bernardo Gomes, para hacer de ella una flauta (BETTENDORF 1909:431). 
La información de que los huesos de los enemigos muertos en los rituales antropofágicos fueron guardados con el objetivo de fabricar instrumentos musicales puede ser encontrada en innumerables relatos europeos sobre la población indígena americana. La novedad es que aquí no se trata de un indio de alguna nación enemiga cuyos huesos fueron convertidos en instrumentos de viento, sino que se trata de misioneros jesuitas. Hubo casos de religiosos asesinados por indios durante la colonización de Brasil, pero ésta es la única información concreta de que hayan sido transformados en flautas. Y que hubiese sido, con esta finalidad, que sus huesos fueran robados por miembros de otra tribu indígena. Después de la muerte de los jesuitas Pereira y Gomes, y a través de sus restos mortales, más sonidos se escucharon en las aldeas del norte colonial.

La cita anterior reafirma el interés que tenían los nativos por los poderes de la religión cristiana, de los cuales parecían querer apropiarse de manera antropofágica, o sea, sin encarnarlos en su esencia, sin seguir su ética, pero valiéndose de ellos para el fortalecimiento de su propia espiritualidad. Tal era el principio del canibalismo: apropiarse de los poderes del guerrero enemigo para después usarlos en el combate contra el grupo del que provenía el prisionero. El campo de batalla no fue la selva, pero sí aquella que era la principal celebración religiosa del otro, la santa misa. Transformar a los padres en instrumentos musicales evidencia que la música era una moneda valiosa a ser utilizada en sus futuros rituales. La muerte de los padres Pereira y Gomes, al mismo tiempo en que altera radicalmente una manifestación religiosa, la mantiene pero a la manera indígena.

Algunos episodios de la historia de la relación entre el padre Antonio Pereira y los indios de la etnia Tapajó pueden aclarar con mayor precisión esta contienda religiosa. Años antes, él pudo haber sellado su propio destino al combatir el culto a los huesos de los antepasados indígenas. Los tapajós guardaban hacía años los restos mortales de Monhangarypy, que significa el primer padre, y le rendían honras y fiestas. El jesuita consideró abusivas aquellas veneraciones, que estarían difamando la santa fe católica, y prendió fuego a la casa que abrigaba el túmulo del ancestro indígena. Tiempo después, su propio cuerpo fue reducido a alimento y sus huesos acabaron siendo utensilios prácticos para los rituales tapajós, inclusive, para sus actividades musicales. Para la desesperación de los jesuitas, los restos mortales de su colega hasta pudieron haber sido aprovechados en las fiestas antropofágicas 
que los misioneros tanto lucharon por exterminar.

El padre Antonio Pereira, al quemar los restos del chamán con el objetivo de eliminar su influencia y de apropiarse del espacio que éste ocupaba en la vida espiritual de los indios, no pudo prever el efecto dominó de sus actos. Quemar los símbolos religiosos considerados herejes era una práctica típica de la Contrarreforma, que encendió hogueras en las plazas europeas contra los desertores de la fe católica. Libros prohibidos, mujeres llamadas de brujas e incluso reliquias indígenas debían ser eliminadas por las llamas purificadoras, lo que supuestamente reforzaría el poder del Catolicismo. Sin embargo, en respuesta, los indios, valiéndose de un procedimiento que para ellos tenía sentido porque formaba parte de su lógica bélica, devoraron a los padres jesuitas, reocupando, en una cadena de eventos antropofágicos, el espacio destinado a las creencias de sus propios símbolos, que ya no se resumían a reliquias en sí sino también a la trayectoria de venganzas a la cual fueron sometidas. Después de quemadas sus reliquias, comieron a los padres en plena misa, transformándolos en participantes de los rituales indígenas que aquellos tanto condenaban. Convertidos en flautas indígenas, los jesuitas sufrieron un proceso que podríamos llamar músicofagia.

Las etnias indígenas rendían culto a los huesos, no de los enemigos, pero sí a los de sus chamanes. Los despojos de los muertos eran símbolos de la existencia de un mundo sobrenatural, y la creencia en sus poderes movía a los indios. De igual forma era para los jesuitas que veneraban las reliquias de sus mártires, las cuales podrían ser objetos con los que tuvieron contacto o los propios restos físicos de los padres. El culto a los huesos, por tanto, estaba presente tanto en la cultura de los indios como en la católica, causando así disputas feroces. En las fiestas de culto a los antepasados indígenas los huesos reverberaban voces del más allá, que muchas veces incitaban la oposición por parte de los misioneros. Los jesuitas, a su vez, intentaban estimularlos a la adoración de las reliquias de los santos católicos. Al contar sobre el destino de los padres devorados, notamos que los jesuitas descargaron en sus tintas toda la crueldad de la trama. La narración de la tragedia podría inclusive colaborar en un futuro proceso de canonización de aquellos considerados los mártires del Nuevo Mundo. La muerte en tierras inhóspitas llegaba a ser deseada por los misioneros, puesto que era casi una garantía de que la víctima alcanzaría la tan honorable santidad. El problema en el caso de los padres muertos en Camunixary sería encontrar y recuperar las reliquias de manos 
de las diferentes etnias indígenas, que las usaban como recipiente de bebidas fermentadas y como instrumentos musicales.

Los huesos humanos fueron objeto de exacerbadas querellas y constituyeron un campo de interacciones y traducciones culturales entre el mundo indígena y el cristiano, ya que en ambos poseía valor especial por su vinculación con lo sobrenatural ${ }^{8}$. Desde el punto de vista católico, la adoración de las reliquias de los mártires se conectaba a la historia del continente a través de casos como la supuesta vida del apóstol Santo Tomás, que habría dejado sus huellas grabadas en piedras en Brasil'. Desde la perspectiva indígena, vale destacar el caso de la veneración de los restos mortales del jesuita Francisco Pinto, que en una operación de transferencia simbólica suscitaron la memoria de los huesos de los chamanes. En el caso de los padres Pereira y Gomes, considerados enemigos, los transformaron en utensilios para el vino y en instrumentos musicales de viento. Del destino de otros religiosos que murieron en el Nuevo Mundo, como el obispo Sardinha, nada se sabe. Podemos pensar, y no sería del todo una fantasía por su posibilidad histórica, que el gran opositor de la música cantada y tocada en las aldeas también haya sido convertido en una flauta indígena.

Al reflexionar sobre las traducciones culturales entre indios y misioneros, debemos insistir con más fuerza en las celebraciones festivas realizadas en las aldeas, como prácticas culturales extremadamente ricas en implicaciones sociales, religiosas y políticas. Ellas despertaban los ánimos de los participantes y envolvían a toda la comunidad en una reactualización mítica, pues con la interrupción de las acciones cotidianas se instauraba el tiempo y el espacio de lo sagrado. En las aldeas ocurrían las fiestas periódicas y las ocasionales, o sea, aquellas introducidas en el calendario litúrgico católico, entre ellas las dedicadas a los santos patrones o las realizadas en la época de navidad y Corpus Christi, y aquellas circunstanciales, entre las cuales se incluyen los llamados recibimientos, paradigmas de las fiestas de las misiones, sobre lo cual hablaremos a continuación ${ }^{10}$.

8 Ver KOK, Glória. 2008. "Memória dos ossos: xamãs e jesuítas em processo de interação simbólica e resistência na América Meridional". Anais Eletrônicos do XIX Encontro Regional de História, Anpuh-São Paulo.

9 Ver CYMBALISTA, Renato. 2006. "Relíquias sagradas e a construção do território cristão na Idade Moderna”. Anais do Museu Paulista: História e Cultura Material. São Paulo: Vol.14, n.2, jul/dez.

10 Ver LUZ, Guilherme Amaral. 2008. "Quando o verbo se faz carne: antropofagia e eucaristia no teatro 
El género del recibimiento, performatizado en las tierras de la América portuguesa, estaba pautado en las tradiciones indígenas al manifestar amistad y respeto a los visitantes, acogiendo al huésped con lágrimas y ofreciéndole alimentación y estadía. Cierta vez, algunos indios viajaron por meses con la intención de traer parientes para la aldea en donde vivían, una de las cuatro bajo la responsabilidad de los jesuitas en la región de Espíritu Santo. En el camino, pelearon y vencieron. A su llegada, fueron recibidos con llanto, comida y música. El escritor jesuita afirma que las lágrimas de los indios eran derramadas por encontrarse estos en un espacio cristiano. De hecho, estar entre los habitantes de una aldea jesuita, menos expuestos a las expediciones de captura de grupos indígenas debería traer cierto alivio y la esperanza de un futuro más pacífico. Sin embargo, la emoción del reencuentro se dio a la manera indígena, sin faltar las manifestaciones musicales. Además de las flautas, ¿serían pequeñas maracas lo que los niños indígenas tenían en las manos?

El padre Domingo Garcia que reside en la Aldea de los Reyes Magos, el cual mandó a algunos indios viejos a más de ciento cincuenta leguas tierra adentro para que trajeran a sus parientes: después de algunos meses vinieron junto a cuatrocientas almas y en el camino fueron favorecidas por Nuestro Señor dándoles la victoria frente a los enemigos. El padre los fue a recibir a algunas leguas con los de su Aldea, llevándoles alimentos, festejando la llegada con música de flautas, y otras parecidas, no podían parar de llorar los unos cuando se vieron en la iglesia listos para recibir la paz, y la libertad tan deseada, los otros, y en especial nuestros padres se conmovieron con el fervor con que estos venían desde tan lejos para la iglesia, los hombres con sus armas, las mujeres con sus hijos en los brazos, y los jóvenes que podían andar con sus bordoezinhos en las manos (RODRIGUES 1599: 473v).

Las fiestas para recibir a las visitas y/o las reliquias estaban, de hecho, entre las más importantes celebraciones del Brasil colonial. Los grandes responsables por la organización de estas fiestas de recibimiento, compuestas de elementos indígenas y cristianos, fueron los jesuitas. Aún a comienzos de siglo XVII, el misionero Luis Figueira relata cómo una vez fue acogido por los indios de Ibiapaba:

jesuítico (América Portuguesa, século XVI)”. Anales Electrónicos de las XII Jornadas Internacionales sobre las Misiones Jesuíticas, Buenos Aires. 
Nos vino a recibir el propio principal en el medio del camino a media legua de la aldea con todos los principales y algunas mujeres con regalos, y ellos todos con sus bocinas, flautas y cascabeles, que son sus instrumentos de música con tanta fiesta y alegría que yo me quedé pasmado. (...) Llegando a la aldea salió un gran tambor que toda la mañana oímos y con sus maracas sonando y cantando, y con esa solemnidad nos hicieron pasar a la casa que nos habían preparado y nos trajeron muchos regalos y muchas músicas y las danzas continuaron durante días y noches; bendito sea el Señor que permite que estos bárbaros sin conocerlo honren a sus siervos sólo por el hecho de ser sus servidores (FIGUEIRA 1940: 120-121).

El padre Figueira fue recibido en la aldea a la manera indígena. Su última frase revela, más que un desconocimiento de la alteridad, una creencia de que los indios honraban a los padres por ser siervos del Dios católico. El recibimiento festivo con música, además, se dio de acuerdo a las costumbres indígenas. En este caso, incluyó cantos e instrumentos de viento y de percusión, inclusive las maracas. En las aldeas jesuitas el recibimiento pasó a ser un momento de pacto entre misioneros e indios, donde se entremezclaban elementos de saludos emotivos y de las entradas europeas ${ }^{11}$. Difundidas en el Viejo Mundo entre los siglos XIV y XVIII, se trataba de representaciones de la entrada de Cristo en Jerusalén y de homenajes que se rendían a la llegada de los miembros del alto clero o de la nobleza (BAUMANN 2008: 14). En la sierra de Ibiapaba, a su vez, el propio Vieira relata la recepción que tuvo en una de las visitas que le hizo a la misión San Francisco Javier:

Después que los padres misioneros e indios de las aldeas supieron que venía el padre sub prior Antonio Vieira, lo fueron a recibir en el camino con los principales con mucha fiesta y danza de los muchachos, y así lo acompañaron hasta la iglesia en donde se tocó la campana, tocando los tabajaras pernambucanos sus charamelas y flautas (BETTENDORF 1909: 123).

La música ejecutada dentro de la iglesia por los tupis cristianos, que habían aprendido composiciones religiosas con los jesuitas, era europea. Fue, de igual modo, interpretada con instrumentos musicales de viento comunes

11 El llanto y el canto estaban también presentes durante los rituales fúnebres. Sigue el trecho de una de las narraciones jesuitas que registran la costumbre indígena: "Cuando alguien muere se invita a todos los parientes para la lamentación, lo que se hace durante varios días de acuerdo con las cualidades del difunto". Carta ânua maranhense de 1696, fólio 427. 
al Viejo y al Nuevo Mundo. La manera de recibir a alguien con fiestas era indígena, con danzas de curumins. Manifestaciones diversas, pero con motivos comunes, produjeron mezclas, como las acciones hechas en conjunto llamadas recibimientos. Era necesaria una relativización de la alteridad para disminuir las distancias entre aquellos sujetos. Se percibe frecuentemente en las fuentes coloniales y en las narraciones de los misioneros la práctica del método jesuita de conjugación de costumbres nativas y europeas, y el deseo indígena por el aprendizaje de la música del otro, relacionado a su práctica espiritual. De esta forma, se fue estableciendo un diálogo religioso entre diferentes mundos simbólicos, que se dio también a través de los sonidos musicales y que resultó en complejas traducciones culturales.

\section{BIBLIOGRAFIA Y FUENTES}

ANTUNES, Miguel. 1696. “Carta ânua maranhense”. Archivum Romanum Societatis IESU (ARSI), Bras. 9, fólios 426-431.

BAUMANN, Thereza. 2008. "Festa na missão: recebimentos e entradas no teatro catequético de José de Anchieta”. Anales Electrónicos de las XII Jornadas Internacionales sobre las Misiones Jesuíticas, Buenos Aires.

BETTENDORF, João Felipe. 1909 [1698]. “Chronica da missão dos padres da Companhia de Jesus no Estado do Maranhão”. Revista do Instituto Historico e Geographico Brazileiro, Tomo LXXII: 1-697.

BLUTEAU, Raphael. 1712-1728. Vocabulário português e latino. Coimbra: Collegio das artes da Companhia de Jesus. (ed. fac-símile http://www. brasiliana.usp.br/dicionario/edicao/1)

CARVALHO JÚNIOR, Almir Diniz de. 2005. Índios cristãos: a conversão dos gentios da Amazônia Portuguesa (1653-1769). Tese de Doutorado em História, Universidade Estadual de Campinas - Campinas.

CASTAGNA, Paulo. 1991. Fontes bibliográficas para a pesquisa da prática musical nos séculos XVI e XVII. Dissertação de Mestrado em Artes, Universidade de São Paulo - São Paulo.

CASTAGNA, Paulo. 1999. "Uma abordagem musicológica da produção literária de Antônio Vieira (1608-1697)”. Cadernos do IEB/USP. Antônio Vieira: o imperador do púlpito: 39-72.

CASTELNAU-L'ESTOILE, Charlotte de. 2006. Operários de uma vinha estéril: os jesuítas e a conversão dos índios no Brasil (1580-1620). Bauru: Edusc. 
CYMBALISTA, Renato. 2006. "Relíquias sagradas e a construção do território cristão na Idade Moderna”. Anais do Museu Paulista: História e Cultura Material. São Paulo: Vol.14, n.2, jul/dez.

FIGUEIRA, Luís. 1940 [1608]. "Relação da missão do Maranhão, 26 de março de 1608”. In: Serafim Leite (org.), Luiz Figueira: a sua vida heróica e a sua obra literária. Lisboa: Agência Geral das Colônias.

HOLLER, Marcos. 2010. Os jesuítas e a música no Brasil colonial. Campinas, SP: Editora da Unicamp.

KOK, Glória. 2008. “Memória dos ossos: xamãs e jesuítas em processo de interação simbólica e resistência na América Meridional”. Anais Eletrônicos do XIX Encontro Regional de História, Anpuh-São Paulo.

LEITE, Serafim. 1943. História da Companhia de Jesus no Brasil. Rio de Janeiro: Instituto Nacional do Livro/ Lisboa: Livraria Portugália.

LEITE, Serafim. 1947. “A música nas primeiras escolas do Brasil”. Revista Brotéria, XLIV: 377-390.

LUZ, Guilherme Amaral. 2008. "Quando o verbo se faz carne: antropofagia e eucaristia no teatro jesuítico (América Portuguesa, século XVI)”. Anales Electrónicos de las XII Jornadas Internacionales sobre las Misiones Jesuíticas, Buenos Aires.

NAVARRO, Eduardo de Almeida. 2005. Método moderno de Tupi antigo: a língua do Brasil dos primeiros séculos. São Paulo: Global.

POMPA, Cristina. 2003. Religião como tradução: missionários, Tupi e Tapuia no Brasil colonial. Bauru: EDUSC.

RODRIGUES, Pero. 1599. “Carta ao Padre Geral”. Archivum Romanum Societatis IESU (ARSI), Bras. 15 II, fólios 473-478v.

VIEIRA, Antônio. 1997 [1654]. Antônio Vieira: cartas (coordenadas e anotadas por J. Lúcio de Azevedo). Lisboa: Imprensa Nacional Casa da Moeda.

VIEIRA, Antônio. 1904 [166o]. "Relação da missão da Serra de Ibiapaba”. Revista do Instituto do Ceará, XVIII: 86-138. 


\section{Sobre la autora}

Graduada en Ciencias Sociales por la UFSC y en Historia por la UDESC. Magíster en Historia Social por la UNICAMP. Actualmente integra el grupo de doctorandos de esta misma institución, bajo la orientación del profesor John Monteiro, con investigación financiada por la FAPESP sobre la música en las aldeas jesuitas de la América portuguesa. Es autora del libro $O$ vapor e o botoque: imigrantes alemães e índios Xokleng no Vale do Itajaí/SC (18501926). Florianópolis: Letras Contemporáneas, 2007.

Dirección: Rua dos Pinheiros, 954, apto 112b. São Paulo-SP, Brasil. CEP 05422-001.

Correo electrónico: luisaw@matrix.com.br 